\title{
EFEECT OF INITAL COMPOSITION DISTRIBUTION ON THE PHASE TRANSFORMATION BEHAVIOR IN THE FE-CR-NI SYSTEM
}

\author{
J. M. VITEK, S. A. DAVID \\ Oak Ridge National Laboratory \\ P. O. Box 2008 \\ Oak Ridge, TN 37831-6376
}

\begin{abstract}
presented at 1995 Fall Meeting of the Materials Research Society November 27 to December 1, 1995, Boston
\end{abstract}

\section{DISCLAIMER}

This report was prepared as an account of work sponsored by an agency of the United States Government. Neither the United States Government nor any agency thereof, nor any of their employees, makes any warranty, express or implied, or assumes any legal liability or responsibility for the accuracy, completeness, or usefulness of any information, apparatus, product, or process disclosed, or represents that its use would not infringe privately owned rights. Reference herein to any specific commercial product, process, or service by trade name, trademark, manufacturer, or otherwise does not necessarily constitute or imply its endorsement, recommendation, or favoring by the United States Government or any agency thereof. The views and opinions of authors expressed herein do not necessarily state or reflect those of the United States Government or any agency thereof.

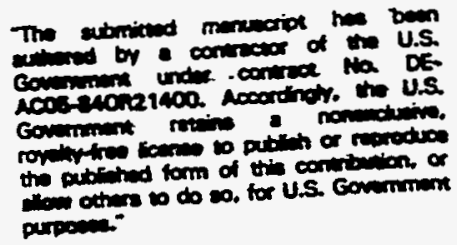




\title{
EFFECT OF INITAL COMPOSTION'DISTRIBUTIONON THE \\ PHASE TRANSFORMATION BEHAVIOR IN THE FE-CR-NI SYSTEM :
}

\author{
J. M. VITEK, S. A. DAVID \\ Oak Ridge National Laboratory, P. O. Box 2008, Oak Ridge, TN 37831-6376, vmj@ornl.gov
}

\begin{abstract}
A finite-difference implicit numerical model was used to study the diffusion-controlled $\alpha-\gamma$ solid-state phase transformation in the $\mathrm{Fe}-\mathrm{Cr}-\mathrm{Ni}$ system. The influence of a non-uniform initial composition distribution was examined in order to assess the impact that non-uniform solute profiles resulting from solidification may have on subsequent transformation behavior in weldments and castings. A significant impact on the transformation kinetics and transformation path was found in some cases. The factors that affect the degree of influence are discussed.
\end{abstract}

\section{INTRODUCTION}

Modeling phase transformation behavior is a rapidly growing field. Such modeling is particularly valuable and desirable for weldments because of the high temperature excursions which weldments experience and the difficulty in properly and accurately evaluating the elevated temperature phase transformation behavior by experimental means. In the case of austenitic stainless steels, solidification of primary ferrite is followed by the solid-state transformation of ferrite to austenite. The ferrite-to-austenite transformation during cooling is typically incomplete, leading to a two-phase microstructure that consists of austenite with 5 to $15 \%$ of residual ferrite. In most cases, the ferrite-to-austenite transformation is diffusion controlled. Thus, it is possible to model this transformation effectively, provided that the diffusion behavior is properly evaluated. For multicomponent systems, the diffüsion-controlled transformation cannot be readily calculated by analytical means. However, numerical methods are ideally suited to tackle such involved problems.

By considering the ternary $\mathrm{Fe}-\mathrm{Cr}-\mathrm{Ni}$ system as representative of the class of austenitic stainless steels, the ferrite-to-austenite transformation has been examined recently for both cast. stainless steels and welded stainiess steels [1-7]. Finite difference methods have been used to follow the transformation behavior in the ternary system during isothermal exposure [1-4] as well as during contimuous cooling $[5,6]$. These studies have modeled the transformation behavior by assuming local equilibrium at the ferrite/austenite interface. Comparisons of the calculations with experimental work have shown very good agreement:[1-3]. Most recently, the transformation behavior in multipass welds has been modeled by examining the influence of multiple thermal cycles [7]. All of these earlier studies have shown that the consideration of a ternary system has a strong influence on the transformation behavior. Unlike simple binary systems, where unique tielines exist at any given temperature, the consideration of ternary systems introduces a range of equilibrium tie-lines. This added degree of flexibility results in many interesting effects. For example, the approach to final equilibrium is often indirect in that ferrite growth may take place initially, followed by dissolution of the ferrite. The change in phase composition as a function of aging time can also be quite complicated, with non-monotonic variations being common. The exact behavior is sensitive to the overall alloy composition, the initial phase compositions, and the thermal history. Modeling is ideally suited for following these transformations and for determining the system response to a given thermal exposure. 
In the eartierinvestigations [1-7], the calculations-were simplified by assuming uniform initial compositions for the ferrite and austenite-:However; in reality, the compositions that are present after weiding or casting are non-uniform as a consequence of solute segregation during solidification. The aim of this investigation was to examine the influence of a non-uniform initial composition distribution on the transformation behavior. Clearly, the final equilibrium condition will be unaffected by the initial composition distribution, but the path and rate at which equilibrium is achieved may be influenced. Results from this study should provide needed insight into the effect that solute redistribution during solidification may have on the solid-state transformation behavior.

\section{COMPUTATIONAL APPROACH}

The model evaluates the diffusion-controiled growth or dissolution of ferrite $(\alpha)$ in a twophase system consisting of ferrite.and austenite $(\gamma)$. Nucleation is not considered since it is assumed that both phases exist at the start of the calculations. Although the actual solidification microstructure typically consists of residual ferrite dendrites in an austenite matrix, the model considered only a planar geometry with a planar interface between the $\alpha$ and $\gamma$ phases. Earlier work has shown that this simplification is justified since the transformation kinetics are essentially equivalent.for these two cases, as long as the ferrite phase is at the core of the cylindrical geometry [6]. The one-dimensional diffusion transformation problem requires the solution of Fick's Second Law.. A mass balance at the interface between the two phases requires that the rate of growth of the $\alpha$ phase is balanced by the net flux of atoms across the interface. For a ternary system, two mass. balances at the interface, for two elements, must be independently evaluated [4]. In the present case, in which the diffusion-controlled transformation in the iron-chromiumnickel system is examined, such a mass balance is evaluated for both chromium and nickel. The. interface compositions for the $\alpha$ and $\gamma$ phases must then be adjusted in an iteration scheme until the interface velocities derived from both the chromium and nickel mass balances are the same.

An implicit, finite-difference method was utilized to solve for the compositions of the two phases as a function of time and distance. Details of the mathematical analysis, including the equations in finite-difference form, are provided elsewhere [4]. An improved algorithm was used to evaluate the interface compositions. [6].

The diffision equations.were evaluated for both chromium and nickel diffusion. In the present analysis, the following assumptions and simplifications.were made:

(a) the diffusion coefficients were independent of composition,

(b) the ferrite and austenite had equal densities (so that compositions could be expressed in weight percent),

(c) the cross-term diffusion coefficients were ignored,

(d) sigma phase formation was not allowed, and

(e) local equilibrium at the ferrite-austenite interface was required.

The diffusion coefficients were temperature dependent. The equilibrium at the interface between ferrite and austenite-was specified. with the help.of the-ThermoCalc ${ }^{\text {TM }}$ program [8]. For a ternary system, the multiple tie-lines in the two-phase, ferrite-plus-austenite phase field provide the necessary flexibility for choosing the interface compositions. Analytical expressions were used to specify the interface equilibrium as a function of temperature and composition and details are provided elsewhere [4]. The expressions for the diffusion coefficients are also given in an earlier publication [4].

Calculations.were performed for isothermal aging at three temperatures: 800, 1000, and $1200^{\circ} \mathrm{C}$. The overall alloy composition was Fe-21Cr-11.3Ni (all compositions are in wt \%). The 
initial average phase comporitions were Fe-30Cr-5Ni for the ferrite and Fe-20Cr-12Ni for austenite - The overall system sizewas $5 \mu \mathrm{m}$ and the initial ferrite size was $0.5 \mu \mathrm{m}$. Five initial composition distributions were considered. In order to simplify the interpretation of the results, only one component was allowed to vary with distance; chromium was arbitrarily chosen as the initially non-uniform component. An exponential composition distribution was superimposed on either the ferrite or austenite, with enrichment or depletion at the interface. Figure 1 shows the five cases (A through $\mathrm{E}$ ) of initial composition distributions that were examined. The maximum enrichment (or depletion) at the interface was set at $22 \%$. For comparison, the transformation behavior for a uniform initial composition distribution was also evaluated (case A). The average phase compositions were kept constant at the values given above.

\section{RESULTS and DISCUSSION}

The variation of ferrite size as a function of aging time at 800,1000 , and $1200^{\circ} \mathrm{C}$ for cases A through $\mathrm{E}$ is shown in Figures 2 through 4. Before examining the influence of the initial composition distribution on the transformation kinetics in detail, a few general comments are in order. Typically, the transformation takes place in two stages. In the first stage, the transformation behavior is controlled by diffusion within the ferrite while the later stage is

(a)

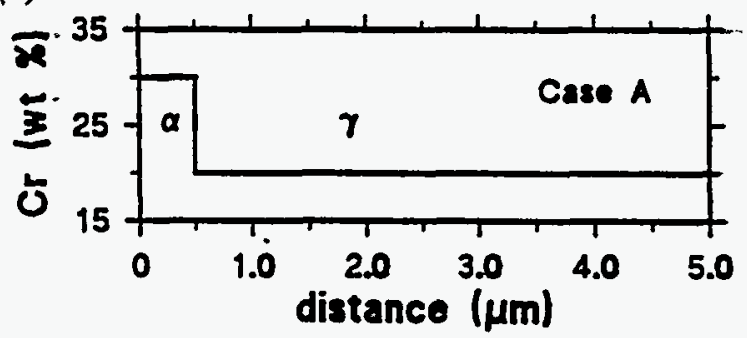

(c)

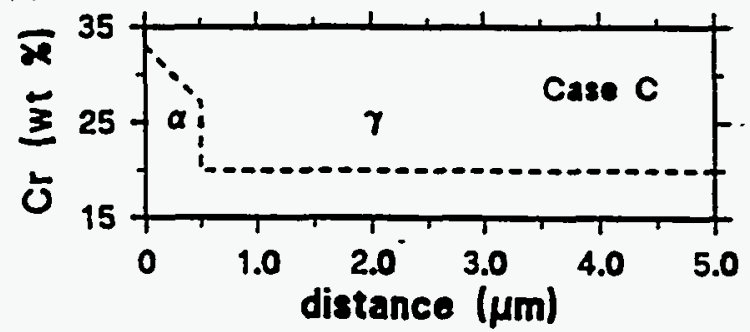

(e)

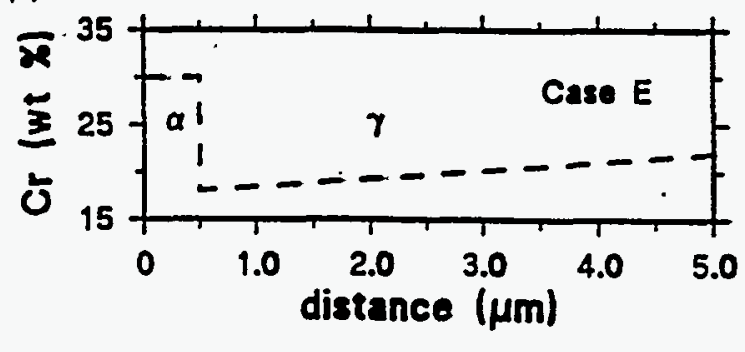

(b)

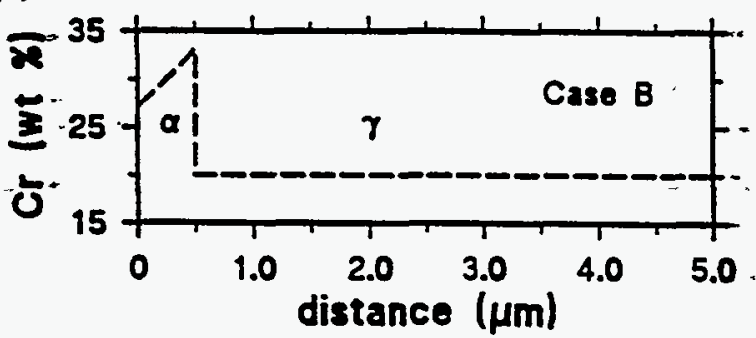

(d)

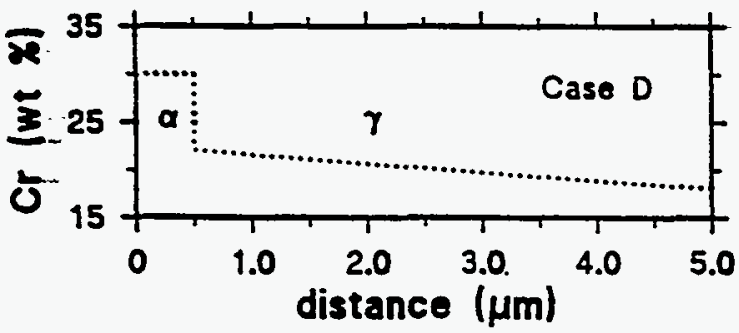

(t)

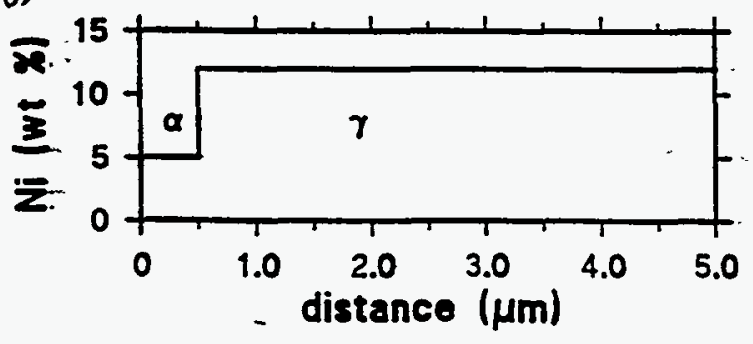

Figure 1 - $(a-e)$ Five different initial chromium composition profiles for cases $A$ through $E$, respectively, and $(f)$ uniform nickel composition profile that was used in all cases. 


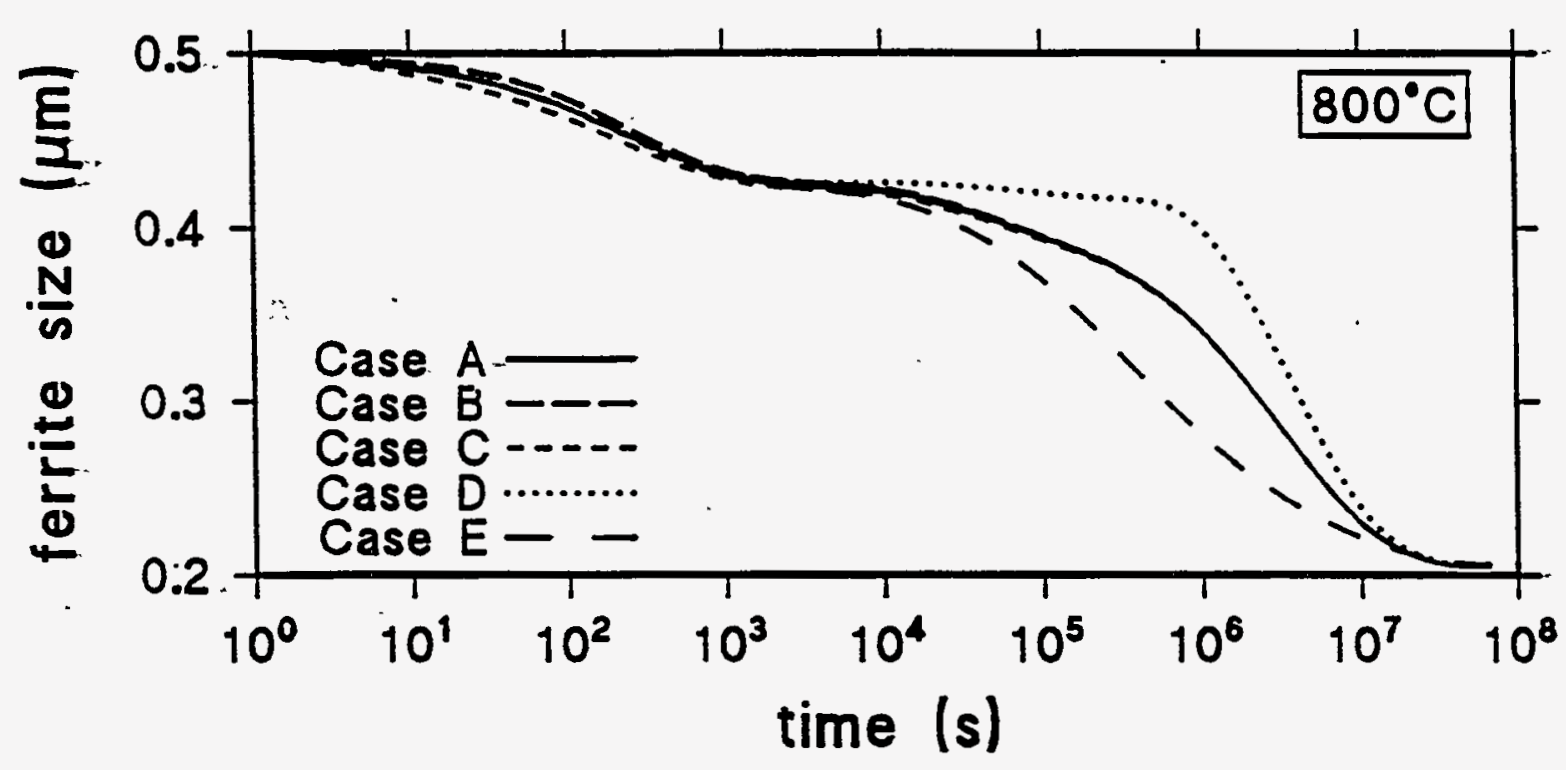

Figure 2 - Ferrite size versus aging time at $800^{\circ} \mathrm{C}$ for different initial composition distributions.

controlled by diffusion within the austenite. Also, in general, errors in the calculations appear in the form of imperfect mass conservation. These errors arise from the initial discretization of the composition, from initially steep gradients that are imposed by the establishment of equilibrium at the interface in the first time step, or from rounding off $[4,6]$. Generally, the errors were less than $0.01 \% \mathrm{Cr}$ and $0.02 \% \mathrm{Ni}$. A change in total system mass resulting from these errors will yield a different final equilibrium state. It can be seen in Figures 2-4 that minor differences in the final ferrite size are only found at $1200^{\circ} \mathrm{C}$. After aging at $1000^{\circ} \mathrm{C}$, the ferrite totally dissolves (a ferrite size of less than $0.01 \mu \mathrm{m}$ was considered to be equivalent to total dissolution). At the other temperatures, some ferrite remained after equilibrium was attained.

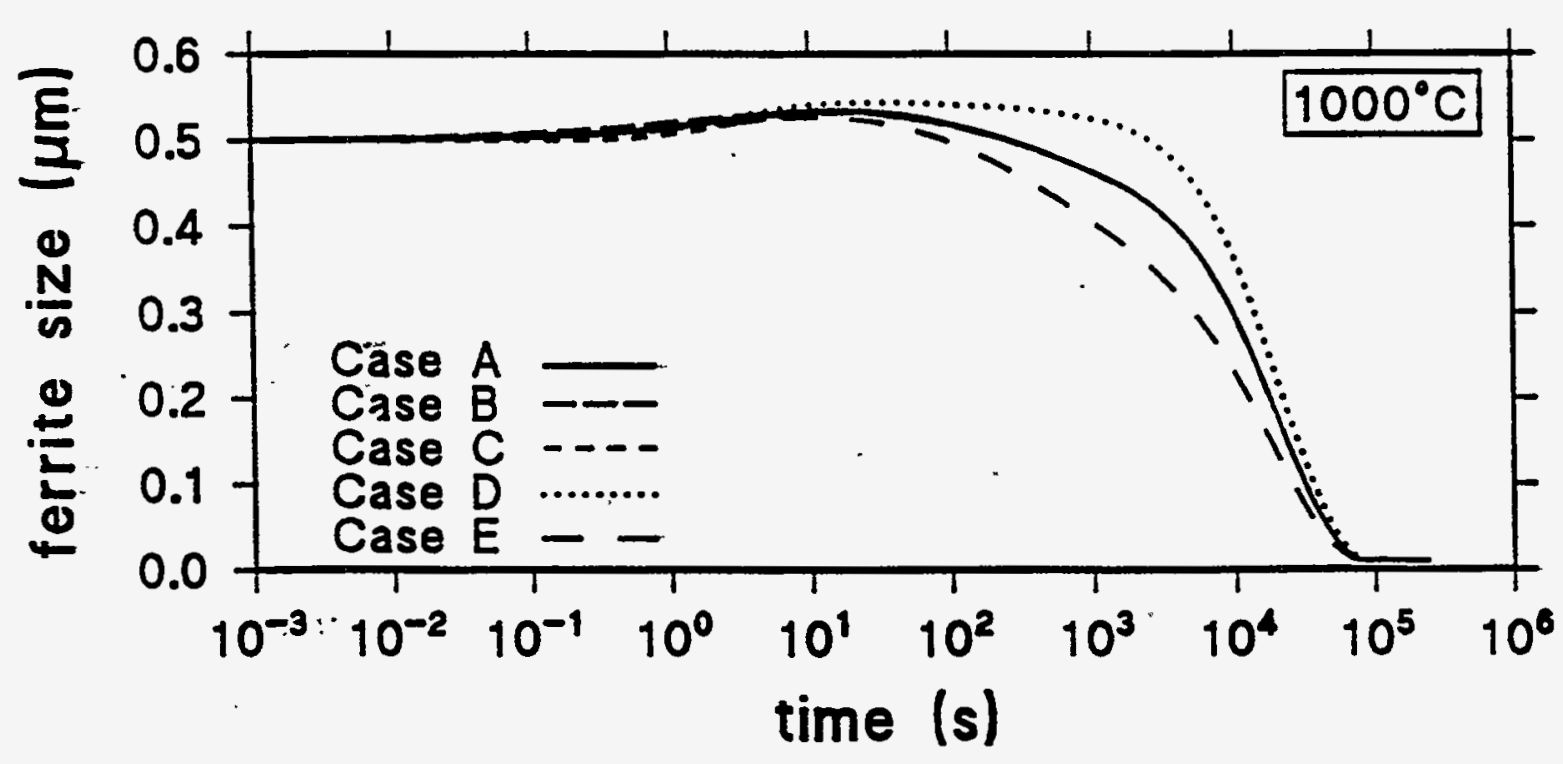

Figure 3 - Ferrite size versus aging time at $1000^{\circ} \mathrm{C}$ for different initial composition distributions. 


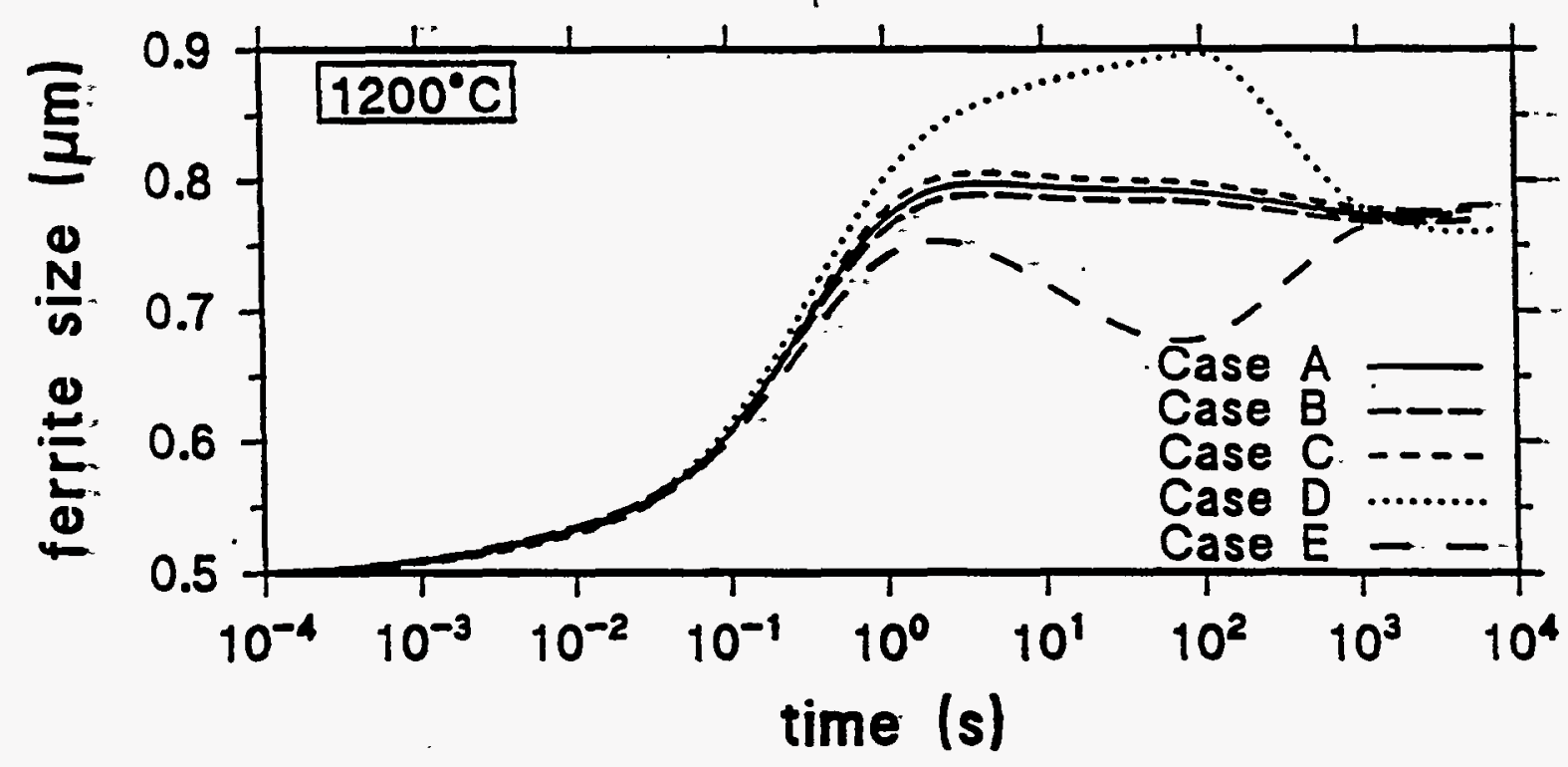

Figure 4 - Ferrite size versus aging time at $1200^{\circ} \mathrm{C}$ for different initial composition distributions.

The results show that for cases $\mathrm{B}$ and $\mathrm{C}$, where non-uniform composition distributions were imposed in the ferrite, only a minor influence was detected. In contrast, a non-uniform austenite composition had a much greater effect: Nonetheless, the same general trends were found for both non-uniform ferrite and austenite compositions. Chromium depletion at the interface (cases $\mathbf{C}$ and $E$ ) led to enhanced ferrite dissolution while chromium enrichment at the interface (cases B and D) favored enhanced ferrite growth. Of course, these effects are only temporary since the overall compositions are the same in all cases and the final equilibrium state must therefore be the same.

The results show that the sign of the imposed initial gradient, in this case the chromium gradient, does not directly influence the transformation behavior. For example, a gradient leading to chromium enrichment at the interface might be expected to result in a net chromium flux away from the interface, which would, in turn, favor ferrite dissolution: However, just the opposite effect was found. In fact, the results can be understood by considering the local composition in the region of the interface rather than the initial imposed gradient. For example, if there is chromium enrichment of one of the phases at the interface, the overall alloy composition in the interface area is higher in chromium. This will result in enhanced ferrite stability since chromium is a ferrite stabilizer. This enhanced ferrite stability would, in turn, promote. ferrite growth compared to the condition without chromium enrichment in the interface region. Mechanistically of course, the interface movement is controlled by:the gradients and resultant net fluxes across the interface. When the composition at the interface is changed, by either chromium enrichment or depletion, then the interface gradients are adjusted correspondingly, to either promote ferrite growth or ferrite dissolution. The key is that these adjustments are not determined by the initial gradient that is imposed by the non-uniform composition distribution, but rather, by the composition of the two phases in the immediate vicinity of the interface.

The fact that the non-uniform austenite distribution has a significantly greater influence than the non-uniform ferrite composition can also be explained. The austenite region was $4.5 \mu \mathrm{m}$ long, significantly greater than the initial ferrite size $(0.5 \mu \mathrm{m})$. In the present analysis, the nonuniform compositions that were imposed were extended over the entire phase so, in effect, the 
chromium enrichment (or depletion) in the austenite extended over a significantly greater distance than the corresponding enrichment (or depletion) in ferrite.. This extended enrichment was balanced by a comparable depletion far away from the interface (see Figure 1). As a result, the consequences of the enrichment persisted for a longer time, and led to a more significant effect. The time over which the enrichment has an influence is comparable to the time required to achieve diffusion distances that are comparable to the scale of the enrichment. Thus, more significant effects would be expected for non-uniform ferrite compositions if the ferrite were larger, and the size of the enriched zone extended to greater distances: Ultimately, the influence of the enrichment/depletion is balanced by the opposite depletion/enrichment far from the initial interface. Thus, enhanced ferrite growth or dissolution is balanced by the opposite effect at a later time, as shown very clearly in Figure 4.

\section{CONCLUSIONS}

The influence of non-uniform initial composition distributions was examined by modeling the diffusion-controlled ferrite-to-austenite transformation in the $\mathrm{Fe}-\mathrm{Cr}-\mathrm{Ni}$ system. It was found that the composition distribution can have a significant influence on the intermediate kinetics of the transformation. The degree of influence is affected by the range of any enrichment or depletion of solute compared to the diffusion distances in the individual phases. It was found that the initial gradients that may exist have little influence on the transformation kinetics. Instead, the critically important factor is the local composition in the immediate vicinity of the interface. The results provide insight into what effect solute redistribution during solidification may have on the transformation kinetics during subsequent thermal exposure in both castings and.weldments.

\section{ACKNOWLEDGEMENTS}

This research. was sponsored by the Division of Materiais Sciences, U. S. Department of. Energy, under contract DE-AC05-84OR21400 with Lockheed Martin Energy Systems.

\section{REFERENCES}

1. M. Kajihara, C.B. Im and M. Kikuchi, in Stainless Steels '91. International Conference on Stainiess Steels, Vol. 1, (Iron and Steel Institute of Japan, Tokyo, 1991), p. 677.

2. M. Kajihara, C.-B. Lim and M. Kikuchi, Iron Steel Inst. Jpn. Int. 33, 498 (1993).

3. M. Kajihara and M. Kikuchi, Acta Metall. Mater. 41, 2045 (1993).

4. J.M. Vitek, S.A. Vitek and. S.A. David, Metall. Mater:Trans: A 26A, 2007 (1995).

5. J.M. Vitek, S.A. Vitek and S.A. David, in Solid $\rightarrow$ Solid Phase Transformations, ed. W.C. Johnson, J.M. Howe, D.E. Laughlin and W.A. Soffá (The Minerals, Metals and Materials Society, Warrendale, Pennsylvania, U. S. A., 1994), p. 201.

6. J.M. Vitek and S.A. Vitek in Phase Transformations During the Thermal/Mechanical Processing of Steel, ed. E.B. Hawbolt and S. Yue (Canad. Institute of Mining, Metallurgy and Petroleum, Montreal, 1995) p. 431.

7. J.M. Vitek, Y. Iskander and S. A. David, to be published in proceedings of Third International Seminar on Numerical Analysis of Weldability, Graz, Austria, 1995.

8. B. Sundman, B. Jansson and J-O. Andersson, Calphad 9, 153 (1985). 